\title{
Reaching hard-to-reach people through digital means - Citizens as initiators of co-creation in public services
}

Harri Jalonen

School of Management, University of Vaasa, Vaasa, Finland

Jussi Kokkola

Turku University of Applied Sciences, Turku, Finland

Harri Laihonen

Department of Health and Social Management, University of Eastern Finland, Joensuu, Finland

Hanna Kirjavainen

Turku University of Applied Sciences, Turku, Finland

Valtteri Kaartemo

University of Turku, Turku, Finland, and

Miika Vähämaa

University of Helsinki, Helsinki, Finland

\begin{abstract}
Purpose - This paper considers the potential of social media for developing public services. The paper approaches social media as a context that can provide information that might otherwise be unattainable. The focus of analysis is on a special hard-to-reach group of marginalized youths who appear to have isolated themselves from society.

Design/methodology/approach - The authors answer the question: How can the experiences of socially withdrawn youth as shared on social media be used to enrich the knowledge base relating to the initiation phase of co-creation of public services? The data retrieved from the Finnish discussion forum are analyzed using the combination of unsupervised machine learning and discourse analysis.

Findings - The paper contributes by outlining a method that can be applied to identify expertise-byexperience from digital stories shared by marginalized youths. To overcome the challenges of making socially withdrawn youths real contributors to the co-creation of public services, this paper suggests several theoretical and managerial implications.

Originality/value - $\mathrm{Co}_{0}$-creation assumes an interactive and dynamic relationship where value is created at the nexus of interaction. However, the evidence base for successful co-creation, particularly with digital
\end{abstract}

(C) Harri Jalonen, Jussi Kokkola, Harri Laihonen, Hanna Kirjavainen, Valtteri Kaartemo and Miika Vähämaa. Published by Emerald Publishing Limited. This article is published under the Creative Commons Attribution (CC BY 4.0) licence. Anyone may reproduce, distribute, translate and create derivative works of this article (for both commercial and non-commercial purposes), subject to full attribution to the original publication and authors. The full terms of this licence may be seen at http:// creativecommons.org/licences/by/4.0/legalcode

This paper was created in conjunction with the Co-creation of Service Innovation in Europe (CoSIE) project. The project has received funding from the European Union's Horizon 2020 research and innovation programme H2020-SC6-COCREATION-2017 under grant agreement No 770492. www.cosieproject.eu.
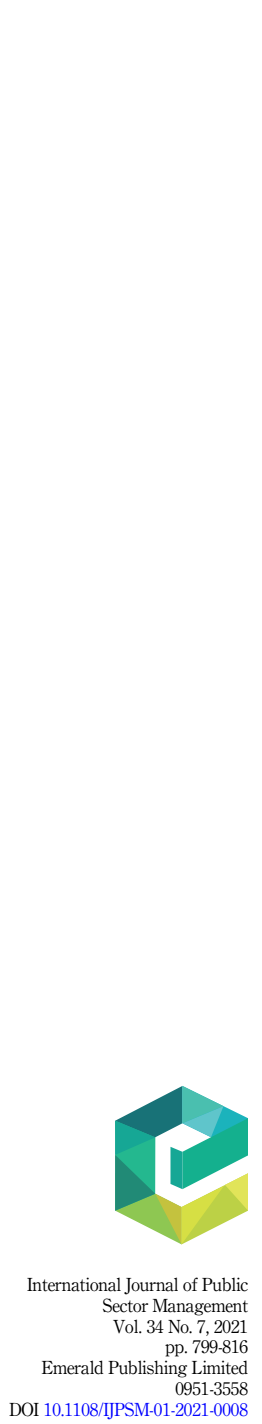
IJPSM

34,7 technology, is limited. This paper fills the gap by providing findings from a case study that investigated how social media discussions can be a stimulus to enrich the knowledge base of the co-creation of public services.

Keywords Co-creation, Public service organization, Social media, Socially withdrawn youths, Digitalization Paper type Research paper

\section{Introduction}

Co-creation is demanding for public service organizations (PSOs) and also for citizens involved in such co-creation. From the PSO's perspective co-creation requires a shift from producing and delivering services based on professional knowledge to customizing services and listening to experts-by-experience. In co-creation, citizens are not seen as beneficiaries but as collaborators whose needs should drive the process from initiation through design to implementation. From the citizen's perspective, the challenge is how to overcome time- and space-related or social and cognitive obstacles to engaging in cocreating activities proposed by a PSO. The challenge may seem impossible to resolve for those who suffer from a lack of tangible and intangible resources. Previous research shows that many intangible resources, such as educational level and interest in politics, increase citizens' intention to take part in co-creation processes (e.g. De Jong et al., 2019). This paper focuses on socially withdrawn youths who are not taking part in any conventional social activities such as education or work. The paper takes a view that youths with a weak attachment to work and education should not be labeled passive bystanders.

Research suggests several remedies for fostering co-creation between PSOs and citizens. Perhaps the most attractive line of investigation addresses the promises of digitalization. While this research stream is still at an early stage, it hypothesizes that digital technology creates the nexus of interaction between the PSOs and citizens. The potential of digital technologies to aid the co-creation of public services has been covered reasonably well in previous studies (e.g. Lember et al., 2019). Iwasaki (2016), for example, argues that social media applications allow for bidirectional exchanges with citizens and government. However, there is a lack of empirical evidence on how citizens can be integrated into the co-creation process. Particularly lacking are empirical studies focusing on vulnerable groups, which are by definition hard to reach (e.g. Brandsen, 2021). Voorberg et al. (2014) systematically reviewed the different roles played by citizens in cocreation and concluded that research has invested less effort in understanding the citizen as a co-initiator than understanding citizens as co-implementers or co-designers. This paper fills the gap by providing findings from a case study that investigated how stories told and shared in social media can be used to enrich the knowledge base aiding the cocreation of public services. During the case study reported herein, the focus was on the initiation phase of co-creation. We did so because it is the initiation phase of co-creation where unheard voices should be introduced to the knowledge held by a PSO. We addressed social media as an underutilized resource for harnessing the needs and expectations of marginalized youths. Using data from a discussion board popular with marginalized youths, this paper answers the following question: How can the experiences of socially withdrawn youth shared on social media be used to enrich the knowledge base relating to the initiation phase of the co-creation of public services? The empirical data consist of messages analyzed using the combination of unsupervised machine learning and discourse analysis.

This article contributes to public service literature in three ways. First, it discusses how digital technology can be used to approach vulnerable groups in the initiation phase of the cocreation of public services and what kind of managerial implications arise when applying digital tools in promoting expertise-by-experience. Second, building on research 
investigating the relationship between online behavior and the social exclusion of youths, this paper provides evidence on techniques for analyzing the content of social media discussions. Third, the paper provides empirical findings illustrating how the assets and the expertise of socially withdrawn youths can be made heard and visible in a way that potentially enriches the initiation phase of co-creation.

\section{Theoretical background}

\section{Citizens in co-creation}

One important landmark of (value) co-creation research was the article by Vargo and Lusch published in 2004. A key premise in Vargo and Lusch's service-dominant logic is that the customer is always a co-creator of value, whereas the role of companies is to offer value propositions. While the underlying logic of service-dominant co-creation is also valid in the context of public services, the assumption of customership does not hold true. Osborne (2018), for example, discusses several differences between being a customer in business and being a user of public services, including the need for businesses to focus on customer retention (whereas returning consumers would be a sign of failure in the public service context), the absence of unwilling and coerced customers in business, multiple end users of the same public service, and the dual role of citizens being both the users of public services and constituents with a broader societal interest. Accordingly, and somewhat paradoxically, being a consumer of public services means having both more and less power over service providers than in business. Marginalized youths are also public service consumers, although the power paradox is less evident.

There are also different strands in studies focusing on co-processes in the public sector: $\mathrm{co}$ creation is sometimes used synonymously with coproduction (e.g. Lopes and Alves, 2020). Conceptually and practically, however, co-creation can be distinguished from coproduction on the basis of how closely citizens are involved in the initiation phase. In coproduction, citizens actively take part in the implementation of the service, while in co-creation citizens are engaged in the ideation and formulation of services. In a coproduction-oriented process, collaboration manifests in the production and delivery of services, but the content of the service is defined by the PSO, while in co-creation, citizens as service users or their representatives also influence the formulation of service content (Voorberg et al., 2014).

Co-creation is based on the ideal of active citizenship, combining the complementary and substitutive capabilities possessed by citizens who use services. Voorberg et al. (2014) distinguished three types of co-creation that differ in their degree of active citizenship: citizens can perform some implementation tasks, decide how the services are designed and take the initiative in formulating specific services. None of the three manifestations of active citizenship would typically be associated with socially withdrawn youths. With reference to Meriluoto (2018) and Brandsen (2021), two specific challenges can be identified. First, activities of co-creation typically mirror the formal decision-making process, which can make it feel unfamiliar or even intimidating to socially withdrawn youths. Second, the accumulated knowledge base on co-creation is dominated by information produced by professionals. The epistemic threshold enables a PSO to choose participants according to its predefined and conscious or unconscious objectives. Instead of seeking experiences that can challenge the status quo, PSOs usually favor knowledge production reaffirming what already exists. In a broader context, there is a risk of establishing a two-track public service provision, where the best-informed and most assertive citizens get the best services (Jilke and Van de Walle, 2013).

While a combination of active citizenship and socially withdrawn youths is literally impossible, the conclusion cannot be that co-creation is meant to be an option only available to those willing and able to participate. The authors would suggest that the question is not whether a PSO should try to reach marginalized youths, but how it might do so. Marginalized
Citizens as initiators of co-creation 
IJPSM

34,7 youths are experts in their everyday lives and have things to say, but if they are to be heard, PSOs must rethink how to listen to them from the very beginning of the process, that being the initiation phase of co-creation. Here, we draw on digital storytelling (Lambert and Hessler, 2018) as applied to developing public services. Digital stories have been successfully used to elicit testimonials and grassroots perspectives on a diverse range of issues and topics, from unemployment through to thoughts on well-being (Trowbridge and Willoughby, 2020). Storytelling is seen in this article as an adequate method to represent different voices and experiences of marginalized youths (Durose et al., 2017).

\section{Digitally enabled co-creation}

Digital technology can reduce the gap between service providers and citizens. Coproductionfocused research has addressed the role of digital technologies more extensively than has cocreation-oriented research. Linders (2012), for example, provides a systematic analysis of social media usage in coproduction and identified three overarching categories - Citizen Sourcing, Government as a Platform and Do-It-Yourself Government - and concluded that in digital coproduction, citizens perform the role of a partner in the delivery of public services rather than that of a customer. Clifton et al. (2020), in turn, provide a systematic analysis of how digital technologies augment coproduction. The study identified several structural and cultural factors acting as enablers of, or barriers to, digitally enabled coproduction spanning government and citizens worldwide.

The literature on digitally enabled co-creation, while nascent, provides some insights that are relevant in the context of this paper. De Jong et al. (2019), for example, found that digital platforms increased citizens' intentions to take part in co-creation processes. Lember et al. (2019), in turn, deconstructed the interactions and identified four elements of the co-creation process on which digital technologies could have an impact. Those include establishing direct interaction, motivating citizens to participate in co-creation, bringing resources to the service and sharing decision-making power between PSOs and citizens. Charalabidis et al. (2014) pointed out that government agencies can deploy passive crowdsourcing to increase the understanding of citizens' needs, issues, opinions, proposals and arguments relating to a particular domain of public policy. Driss et al. (2019) took a step further by suggesting that social media could accelerate citizens becoming government policymakers through the capacity to enable citizens to create, share and comment on issues in a way that is uncontrollable. Casula et al. (2020) addressed the question of how digital technology can support the co-creation of public value in coproduction activities and concluded that instead of focusing on the technical functions, the value of digital technology emerges when digital technology resonates with ancillary values of the relation between the people and the institution.

The important point we seek to impart is that previous research on using digital technology whether in coproduction or co-creation does not address vulnerable citizens. Casula et al. (2020) suggest that to reach marginalized youths through digital means, it is important to focus on the level of affordance. Casula et al. (2020) define affordances as "not just the perceptual features of an artifact but more generally the relations between people needs/tasks/purposes and features of technology." The same study suggests that the affordance approach emphasizes the social context of technology use in recognition that technology supports ancillary (ethical) values. The affordance approach lends itself to understanding the online behavior of socially withdrawn youths. In this paper, we take a view that the affordance value of social media for socially withdrawn youths resides in providing them with a social context where they can anonymously produce and reproduce "anti-social" behavior. This view aligns with emerging studies suggesting that online discussion forums offer socially withdrawn youth a safe space in which to voice their stories in any manner they deem appropriate (Vainikka, 2020). 
The strengths-based approach to socially withdrawn youths

Vulnerable youths have traditionally been seen through problem-based lenses. This approach has not facilitated creating opportunities for youths to thrive. The problem has been that youths' experiences have been evaluated against norms and practices set by adults (Iwasaki, 2016). Recently, the focus has shifted more toward strengths and assets (Lind et al., 2019). Positive youth development (PYD) theory and practice draw on positive psychology and emphasize youths' strengths, resources and opportunities (Larson, 2000). Potential risks and challenges are not dismissed but rather seen as a part of the youths' social habitat (Sanders et al., 2015).

Marginalized youths' strengths manifest themselves in many ways, such as trust and a positive attitude to opportunities (Ponciano, 2013) and also creativity, stubbornness and the acceptance of others (Nott and Vuchinich, 2016), loyalty, empathy, altruism and a willingness to influence (Lind et al., 2019) and a strong sense of purpose and willingness to overcome challenging situations (Sumner et al., 2018). Resilience is embedded in the PYD approach and understood not only as a personal capacity to overcome the negative effects of a harmful situation or experience but also as the capacity of a person's social circle to provide opportunities to young people who have been mistreated (Sanders et al., 2015). The PYD approach highlights the importance of the social and cultural context and the recognition of opportunities for growth and development (Sanders et al., 2015). Accordingly, PSOs may be considered assets that can enhance resilience among vulnerable youths (Heinze, 2013). A meaningful inclusion is one of the key concepts in the PYD as it seeks ways to exploit young people's capabilities in order to facilitate their becoming contributing members of society (Iwasaki, 2016).

We combine the role of stories with a strengths-based approach (e.g. Baron et al., 2019). We do so because the strengths-based approach not only promotes a holistic understanding of peoples' needs but also acknowledges that citizens' have intangible resources, such as knowledge, experience and networks, that should be integrated into the co-creation of public services. In contrast to the deficit-based approach in which a PSO encourages citizens to take action that fits the service's priorities and not their own (Wilson et al., 2018), the strengthsbased approach takes into consideration the entirety of individuals' abilities and their circumstances (Baron et al., 2019).

While service user involvement has garnered support in public services including those targeting youths in vulnerable positions (Mulvale et al., 2019), it is key to emphasize the importance of making the participating group as diverse as possible, trying to find new ways to include the "silent voices": those who do not want to attend or are completely beyond the reach of the service system. As socially withdrawn youths are especially hard to reach, there is a need for new innovative research approaches to improve the understanding of their preferences (Li and Wong, 2015), to which end social media channels provide an appropriate option (Husu and Välimäki, 2017).

\section{Research methods and data analysis}

The leading idea of the paper - social media discussions can be used to enrich the knowledge base relating to the initiation phase of co-creation of public services - was formulated through exploring the conversations on an online forum in Finland that offers socially withdrawn youth a community of support by sharing their thoughts and concerns. Abductive reasoning logic (Aliseda, 2006) utilizes a dialogical process of theory and practice to understand the target phenomenon. In this paper, this meant that a citizen view on co-creation combined with the literature on digitally enabled co-creation and a strengths-based approach to marginalized youths formed an interpretative framework through which validity was examined based on empirical data (Figure 1). Data-driven discourse analysis was supported by the research team's experiences of utilizing social media in various inclusive projects.
Citizens as initiators of co-creation 
IJPSM 34,7

804

The empirical data consist of messages published during 2018 and 2019 on Hikikomero, an anonymous chat room that is part of the Ylilauta discussion forum. Applying the principle of freedom of speech, the forum covers topics from all walks of life including users' assessments of the quality or the lack of public services. In terms of the classification provided by Mergel (2016), the Hikikomero forum can be defined as a social sharing application. The forum has tens of thousands of users who access several themed chat rooms. The work of Haasio and Naka (2019) suggests that the majority of users are likely to be between 16 and 30 years old. The forum's administrator defines the chat room as a peer group for depressed and socially withdrawn people. It is meant to cater to people who find everyday social interaction difficult. While not all users in the forum are hikikomoris who withdraw from society and seek extreme degrees of isolation and confinement (Furlong, 2008), the assumption is that the young people who voice their opinions in Hikikomero do not participate in conventional co-creation activities such as workshops and citizens' juries. Withdrawal from conventional social interactions, however, does not mean that those who have withdrawn do not have anything important to say on societal issues.

The empirical data were gathered and analyzed in five consecutive phases (Figure 2).

In the first phase, a three-person research group explored messages published in the Hikikomero chat room. The exploration phase showed that Hikikomero is a peer group where users share their experiences and opinions about public services. The affective tone of most messages in the test sample was negative, thus illustrating the problems of getting services faced by the users. This finding is in line with the negativity bias in human perception and judgment (Bebbington et al., 2017). At the end of the first phase, a total of 76,305 messages were downloaded from the database owned by a company that gathers hundreds of thousand messages written in Finnish and published on different social media platforms on a daily basis.

In the second phase, the research group utilized a tailored digital tool to identify words that were used to describe the access to and quality of social and health care services. At the end of the second phase, 11 Finnish search terms were selected ("Kansaneläkelaitos" = Social Insurance Institution of Finland; "KELA" = an acronym for Kansaneläkelaitos; "nuorisojärjestö" = youth organization; "nuorisotyö" = youth work; "sosiaalitoimisto" = social services center; "sossu" = a slang expression for "social services center;" "TE-toimisto" = Employment and Business Services; "työkkäri" = a slang expression for "TE-toimisto;" "Diakonissalaitos" = Deaconess Foundation; "Vamos" = youth services project run by "Diakonissalaitos").

In the third phase, we performed topic modeling (Blei et al., 2003), a technique based on unsupervised machine learning (Shalev-Shwartz and Ben-David, 2014). Topic modeling permits the analysis of texts and the identification of the themes and structures of discourses. Topic modeling addresses documents (Hikikomero messages in this study) and words (particularly nouns and verbs in this study) as units of analysis. The method assumes that each document is a collection of topics and that each word has a certain likelihood of featuring

Figure 1.

Abductive reasoning and the research process

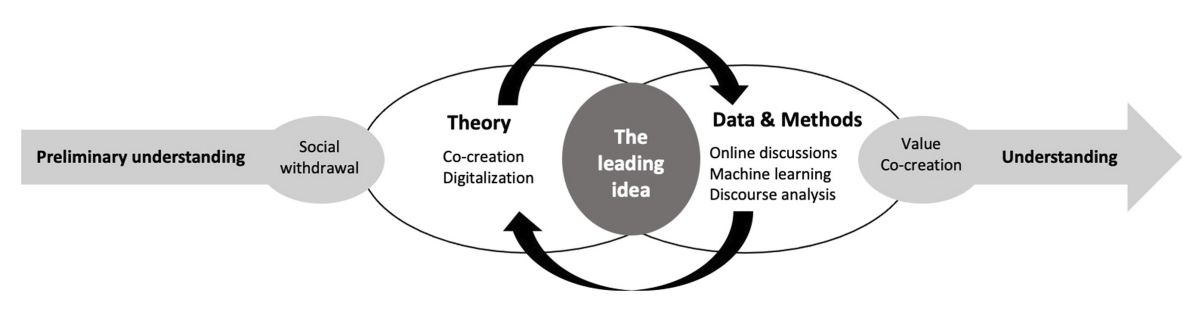




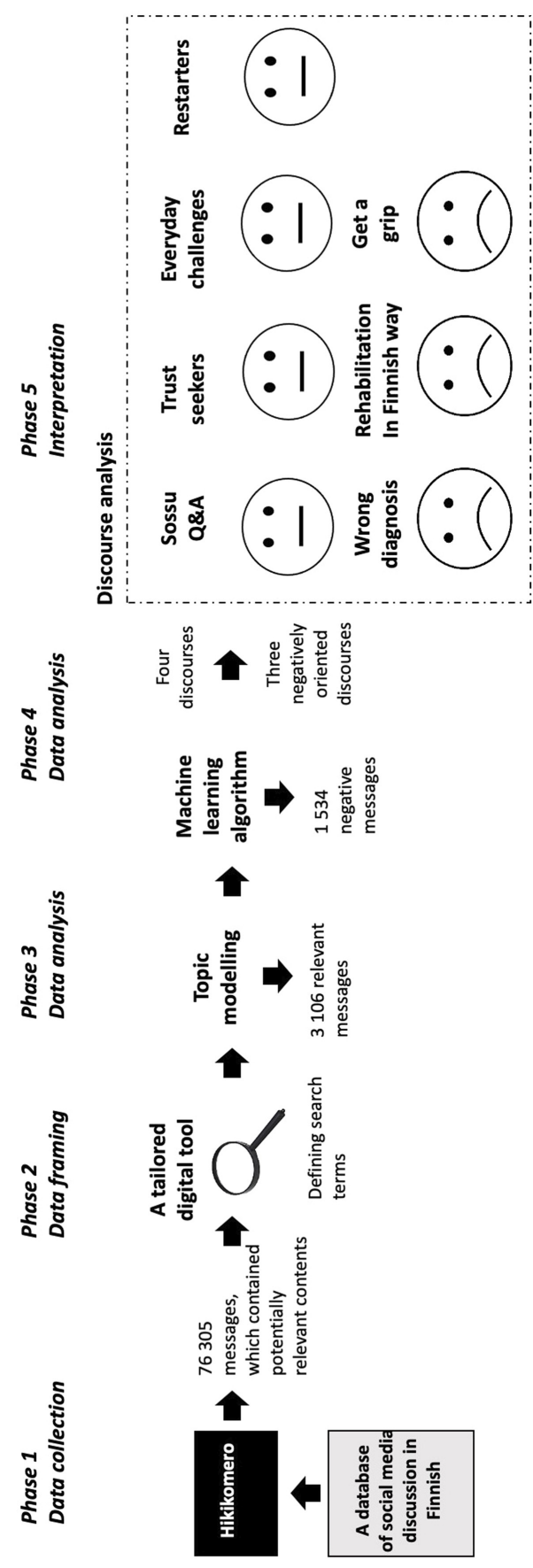

Citizens as initiators of co-creation

805

Figure 2. Overview of data analysis 
IJPSM

34,7

806

in the topic (Puschmann and Scheffer, 2016). Applying topic modeling helped identify 3,106 messages (of 76,305 messages) that were relevant in the context of the paper.

In the fourth phase, those 3,106 messages were categorized using the dictionary created for this study. In line with the research objective, we were interested in messages that described problems or challenges faced by the users. We identified a total of 1,534 messages with negative sentiment. Subsequently, with the help of a machine learning algorithm, we analyzed the discourses and the sentiments expressed in all messages $(3,106)$ and separately, the negatively oriented messages $(1,534)$. The identified discourses represented different linguistic features. Sentiment analysis was deemed an appropriate method to analyze the polarity of discourses. The method refers to the use of natural language processing, text analysis and computational linguistics to identify and extract subjective information from discourses (Liu, 2012). Typically, the aim has been to analyze the attitude of a speaker or a writer. It has been suggested that sentiment analysis can be useful in public service development because it can reveal citizens' dissatisfaction with the services provided for them by PSOs (Jalonen, 2016). The balance between the parsimonious principle and goodness of fit appeared to be offered by four discourses (see the next section). These were extracted via a latent Dirichlet analysis employing Gibbs sampling (Griffiths, 2002). Differences between discourses were statistically significant (sig. <0.01) (See Appendix).

The fifth phase consisted of qualitative discourse analysis focused on the ways in which the users described their experiences of public social and health care services. One of the theoretical starting points for discourse analysis is the assumption of the constructive nature of language use in social reality. When we use language, we create meanings; we construct objects that we talk or write about (Mills, 2004). The identification and recognition of the relationship between social reality and online material discourses are a prerequisite for online discussions being used in the co-creation of services. In online discussion groups, information is built communally in interaction with other users (Jones, 1998). In the case of the Hikikomero-material, the interaction emphasizes context. Hikikomero's individual language register creates a counterbalance to the formal and concern-focused way of speaking about marginalized youth. In discourse analysis, an invisible audience can be taken into account, for which the speaker argues, preparing in advance for possible counterarguments (Potter and Wetherell, 1994). In our material, the assumed counterarguments are generally either ignored or verbally torn to shreds. Common to the language use registers used in the material is the anarchism and clannish way of speaking, which is typical of network subcultures. All discourses identified from the material utilize the affective and experiential challenging of power publicity in a manner typical for counter-publicity (cf. Dahlgren and Alvares, 2013).

Using an online forum as a source of data raises ethical considerations, as participants have not been able to consent to the use of their posts as data. However, the Hikikomero is anonymous and public and includes a disclaimer that the posts may be used as research material. We have respected the participants' privacy by not individualizing any writers or providing any identifiable information about them. The text extracts were translated from Finnish into English, meaning that the data do not exist in the same format on the Internet as in this article.

\section{Findings - the main discourses arising from the data}

People in Finland largely share the principles and values that are the building blocks of the Nordic welfare model. The cornerstones of the model are nondiscrimination and equality; health, well-being and education services being financed through tax revenue; high social mobility; and an active civil society (Norden, 2021). Despite addressing social withdrawal being among the goals of several prime ministers' programs envisioning a fair, equal and 
inclusive Finland, social withdrawal among young people has been an issue in Finland since the 2000s. No one knows exactly how many marginalized youths there are in Finland at the moment, but the Finnish Institute for Health and Welfare estimated the figure at around 50,000 , which roughly equates to the birth cohort of one year in the country.

The discourses and emotions embedded in the material often do not appear as clear entities. In general, the construction of weakly defined initial hypotheses is well suited for discourse analysis. It is natural to raise hypotheses about the regularities observed in the data during the research process as the subject of a more detailed analysis (Bryman and Burges, 1994). Next, we consider the most important themes that have been separated from the material using the algorithm and the discourses outlined based on them. Based on topic modeling at the level of the entire body of material, the four key discourses were "Sossu Q\&A," "Trust seekers," "Everyday challenges" and "Restarters."

The "Sossu Q\&A" discourse emphasized peer support in applying for various grants. Although the discourse was named so as to explicitly refer to the social agency and services, in this context, "Sossu" is synonymous with all the services and support to which the interlocutors may be entitled. Users were largely aware of which branch of the service system they should apply to for support. This finding resonates with findings on youths' social habitat (Sanders et al., 2015). In terms of sentiment, the discussion was generally positive. By sharing and receiving tips and speculating on their options, users in a way strengthened their collective resilience (Sanders et al., 2015). There was also a strong kind of Robin Hood mentality associated with the discourse. The rich-to-poor way of speaking was often strongly present with humorous stories. This kind of communication represents initiative, which originates from everyday experience (Larson, 2000).

Kela Gold is a bit of a bad designation. I developed the table if the subsidies paid by Kela were named in the same way as credit cards.

Kela Basic Gold (KBG) (income support only)

Kela Basic Gold $++(\mathrm{KBG}++)$ (labor market support, income support, and housing support)

Kela Public Labor Gold (KPLG) (labor market support, income support, housing support, travel allowance, expense allowance)

Kela Limited Time Platinum Executive (KLTPE) (rehabilitation allowance, pensioner's housing allowance, guaranteed pension)

Kela Diamond Executive Premium Platinum Superior Black (KDEPPSP) (national pension, pensioner's housing allowance, guaranteed pension)

The "Trust seekers" discourse raises concerns about livelihoods, housing and seeking help from parents. Messages classified in this category in some way convey the need for care and caring. Coping with everyday care and medical expenses was a typical concern. The discourse emphasized feelings of anger, fear, disgust, joy, sadness and confidence. Both negative and positive sentiments feature. The following extract is a representative example of how online discussion forums offer youths a safe space in which to find their voice and communicate (Vainikka, 2020; Casula et al., 2020).

A few years ago, I stopped lying and explaining to everyone. So, I've been telling it straight that I live on the Kela support and I'm mostly laying at home. It's kind of a relief and liberating when you do not need to try to keep up the act.
Citizens as initiators of co-creation 
IJPSM

34,7

\section{8}

The "Everyday challenges" discourse emphasized the central role of the service system. The functioning of support systems was seen as a matter of life and death. If the system provided a safety net, then the conditions for life existed. On the other hand, cutting support can cause a collapse, at least at the text level in the context of a single message. Trust was a key feeling, for both good and bad. From the PYD perspective, users expressed a willingness to overcome the situation (Sumner et al., 2018).

I got a negative rehabilitation support decision. Arguments were the usual (. . .) I think B-opinion was shockingly crap, it did not even describe my symptoms, it only stated when I was in the hospital ward (. . .) Next week I have a doctor's appointment, I'll ask for a new opinion and if similar shit comes then how big of a process is changing the doctor? (. . . It gets awkward when having to meet a new person who knows nothing about me.

In the "Restarters" discourse, a sense of anticipation is discernible. One key theme was employment. How can I get a job? Where to find jobs? Where to get help for a fresh start? In this way, the future was not just seen as a steady gray color or a struggle against the system, but there was an acknowledgment of the possibility of some form of normalization. While their life situation seems unbearable, many users develop trust and a positive attitude to their options (Ponciano, 2013).

I got support from Kela for psychotherapy. It has been a big help to me. It's weird how you still as an adult stick to a child's loyalty to parents, whatever they were. A therapist recently in a session called my father's acts sadistic when I described my childhood experiences. As soon as someone else said so, things got a whole different weight. (. . .) Throughout life, I scourged myself over the fact that I am an incapable loser. Now, empathy for myself has slowly begun to develop.

All four main discourses include positive sentiments, and there is a sense of communality present in the messages. A strengths-based approach (Baron et al., 2019) offers a lens that can detach the stories in our data from stereotypes and the stigma often associated with socially withdrawn youths and also create a viable foundation for co-creation. As online social networks have been proved to encourage active participation in a community, the means of discussion and the rising themes found on such networks could be more concretely incorporated into the design of public services (e.g. Vyas and Dillahunt, 2017).

When looking at the negatively charged messages, three more detailed discourses emerge from the material: "Rehabilitation in Finland," "Get a grip" and "Wrong diagnosis." Messages with a negative sentiment were often at central when considering how different services could be developed. The pain points of the service system can be outlined from the total number of messages, but the examination of negative messages gives more depth to the analysis. For example, in the "Wrong diagnosis" discourse, among the most important emotions that surfaced were fear and distrust. Distrust in the service system was strong, as the discourses contained no trust on fair decisions. The trappings of bureaucracy were always present.

Fear was the most fundamental feeling emerging from the discourses labeled "Rehabilitation in Finland" and "Get a grip." In the latter, anger also came to the fore alongside strong echoes of self-made person mentality. Complainers were seen as weak whiners, and the decision to live on social support was the result of a rational chain of reasoning. The Finnish welfare society was most severely criticized in the messages that counted in the "Rehabilitation in Finland" discourse. The ability of the Finnish service system to support the most vulnerable was not highly valued.

The institutions of the welfare state were not spared sharp criticism because the focus was on the exploitation of the service system, the difficulties in the service encounter, the lack of trust, coping with everyday life and the search for hope. The findings of this study echo the literature suggesting that the design of public services does not fully take account of the experience of the country's youth (Iwasaki, 2016). 


\section{Discussion and conclusions}

This paper has illustrated how socially withdrawn youths can be potential contributors to the co-creation of public services. For the nexus of co-creation to happen, there is a need to integrate professional knowledge with experimental knowledge (Figure 3). Social media discussions and stories dealing with the availability, access and quality of public services even acrimonious ones - can be deemed testimonials that could enable PSOs to identify the bottlenecks in the service delivery process.

The identification of problems, however, is a necessary but not sufficient condition for improving service delivery. To overcome the challenges of making socially withdrawn youths real contributors to the initiation of co-creation of public services, this paper offers three findings.

First, socially withdrawn youths have assets that manifest themselves in various sets of skills, experiences and relationships. Instead of seeing marginalized youths as objects, the strengths-based approach addresses them as experts in their own lives. While experts-byexperience can offer valuable knowledge that can be applied to the initiation phase of cocreation of public services (Meriluoto, 2018), the challenge of working with marginalized youths is in ensuring that their experiences can be shared. Previous studies of co-creation provide only limited evidence on how to materialize the potential related to the assets of socially withdrawn youths. Unless identified by PSOs, these assets remain untapped and will not deliver their full potential. The case study shows that social media provides a digital sphere through which to reach the unreachable. By combining unsupervised machine learning and discourse analysis, this study provides evidence on a method that can be applied to identify expertise-by-experience from the digital stories shared by marginalized youths. In a broader sense, the paper argues that digital spheres should not be allowed to become contexts that only intensify the exclusion and marginalization of those who are already vulnerable.

Second, using unsupervised machine learning to make sense of "hikky" discourses is consistent with efforts calling for greater use of artificial intelligence in the public sector (OECD, 2019a). The current research illustrates that digital technologies can be used to capture large datasets, creating the big picture and framing the data in a meaningful way. The use of social media discussions in the co-creation of public services is also in line with the OECD's (2019b) policy recommendations, which emphasize, among others, dialogue between government and citizens and the active collection of civic feedback. However, many managerial tasks need to be prioritized to harness the full potential of digitality, which includes, but is not limited to, acquiring technological expertise, the creation of dynamic and agile organization cultures, encouraging personnel to experiment and boldly applying new and innovative approaches to reach the unreachable with new tools.

Third, the Hikikomero discussions illustrate the diversity of diverse reasoning offered by marginalized youths in their evaluations of public services. The same service can be justified

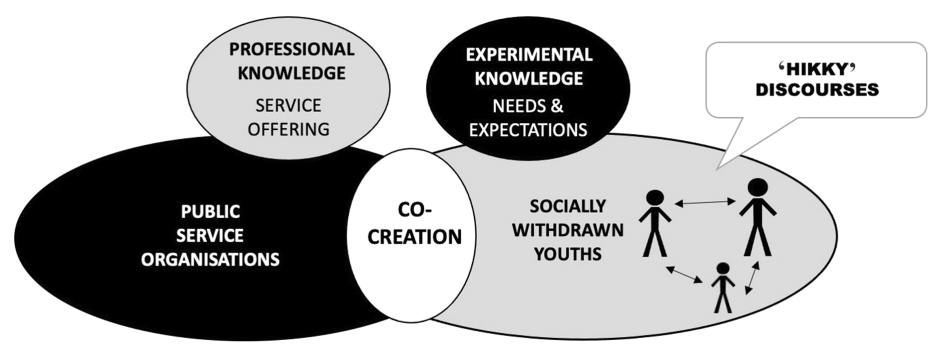

Citizens as initiators of co-creation

809 
IJPSM

34,7

810

for many different reasons and, correspondingly, the acquisition of very different services can be justified for similar reasons (Boltanski and Thévenot, 2006). Hikikomero case shows the importance of acquiring different perspectives when setting the objectives of the public service systems. As the case illustrated, the politically relevant discourses may be very different when looked at from the perspective of marginalized groups. These viewpoints may easily be forgotten or ignored if the knowledge base for decision-making is formed based merely on the opinions of the active and participatory elite. To that happen, marginalize youths must be treated as "testimonial providers," "thinking people" and "asset-holders" (Bovaird and Löffler, 2012), not as "unwelcome truth-tellers" and "wild participants" (Meriluoto, 2018). It may sound like a truism to say that every youth is an expert on her/his own life; however, in the context of co-creation, it has a special meaning. When socially withdrawn youths are seen as initiators of improvements, they not only provide valuable information on their experiences of public services, but they are also empowered and made to feel valued (Healy, 2000). This also suggests asking questions such as what kind of value justifications are offered for co-creation, by whom they are offered and how they influence the process. The analysis of expertise-by-experience offers a means to investigate different methods of value justification in different contexts, and it may therefore be used to introduce value-focused thinking in public service provision.

The paper also proposes two managerial implications. First, reaching socially withdrawn youths can be considered a step toward a more inclusive and equal society. Having their voices heard makes the group visible and may help with creating services and practices that the PSO cannot devise and implement alone. The approach offers a new perspective on cocreation, that of passive participation. This appears to be a win-win situation as the PSO receives valuable information from the social media platform and the individuals using the platform benefit from peer support. This interpretation changes the traditional value conception of co-creation and places the PSO in the passenger seat. Digital technology enables and supports performance dialogue (Laihonen and Rajala, 2020), can break information silos and may help a PSO to recognize and deal with complex societal problems. By injecting new information into the dialogue, and by offering new perspectives and increasing the awareness of service providers, such dialogue may significantly foster the cocreation of public services. This offers the PSO a new type of learning opportunity and is able to construct a different reality and to generate cohesion between the perspectives of service providers and citizens in need of a service. The performance dialogue is implicitly embedded in the co-creation process, but the significance of necessary cultural change is not always acknowledged when engaging in a new type of performance dialogue (Laihonen and Mäntylä, 2017). Especially in the case of the technology-led dialogues discussed here, the PSO loses control over the co-creation process and the development of new structures and capabilities will be a requirement for making use of all the new information gained.

Second, to integrate testimonials into co-creation processes, PSOs should develop methods through which they can avoid selective exposure, defined as the tendency to attend to messages that are consistent with existing knowledge (cf. Rogers, 2003). Leaning on Uppström and Lönn (2017), this paper suggests that co-creation can be supported by using boundary objects. Being "at once material and processual" (Star, 2010), boundary objects provide a window to the everyday life of socially withdrawn youths. The emerging view, then, can be used to spur discussion in conventional co-creation events. Boundary objects help to understand citizens' "lived knowledge" (Healy, 2000) and shed light on the small world of the socially withdrawn youths (Haasio and Naka, 2019; originally Chatman, 1991). Boundary objects help the management level to understand the reality and restrictions of the socially withdrawn and to an extent share a common language with them. The approach would help understand the situation and challenges facing the socially withdrawn youth cohort and enrich the public service providers' knowledge of them. 
This research has its limitations. First, it is clear that unsupervised machine learning is not a silver bullet that will resolve the challenges of analyzing discourses. Understanding the nuances of texts necessitates interpretation by a human, which, in turn, opens the door for subjective interpretations and casts doubt on the validity of the analysis. In this paper, we have managed this challenge by undertaking the discourse analysis as a three-person research group. Second, narrowing the analysis to the messages on the Hikikomero forum is a reasonable solution given the research task but at the same time was a choice that impaired the usability of the results. For young people, a strict divide between the face-to-face and online worlds is no longer relevant, as their digital presence is so intertwined with the rest of their lives. For the same reason, the findings of the study cannot be generalized to other vulnerable groups such as elderly people. Third, the mostly anonymous and offensive messages contain many outbursts. The previous research has found that engaging in counter-publicity is most typical in anonymous discussion forums. The logic and rationale for blaming are often vague, making it difficult to plan remedial action. Consequently, there is a need to test the typology created in this study in other types of social media environment. Fourth, previous research has identified cultural differences in social media behavior (Bonsón et al., 2015). Therefore, caution is advised in any attempt to generalize the findings from the current study conducted in a single country.

The most significant topic for further research relates to the integration of the voice of young people at risk of exclusion into the co-creation of services. Recognizing speech patterns offers a way to ensure that the voice of young people is also reflected in the design and production of services. This, in our view, is an aim that would require support from actionoriented case studies seeking to develop the target PSOs by influencing their practices.

\section{References}

Aliseda, A. (2006), Abductive Reasoning. Logical Investigations into Discovery and Explanation, Springer, Dordrecht.

Baron, S.T., Colombian, C. and Pereira, T. (2019), Strengths-based Approach: Practice Framework and Practice Handbook, DHSC, London.

Bebbington, K., MacLeod, C., Mark Ellison, T. and Fay, N. (2017), "The sky is falling: evidence of a negativity bias in the social transmission of information", Evolution and Human Behavior, Vol. 38 No. 1, pp. 92-101.

Blei, D., Ng, A. and Jordan, M. (2003), "Latent Dirichlet allocation", Journal of Machine Learning Research, Vol. 3 Nos 4-5, pp. 993-1022.

Boltanski, L. and Thévenot, L. (2006), On Justification: Economies of Worth, Princeton University Press, Princeton.

Bonsón, E., Royo, S. and Ratkai, M. (2015), “Citizens' engagement on local governments' Facebook sites. An empirical analysis: the impact of different media and content types in Western Europe", Government Information Quarterly, Vol. 32 No. 1, pp. 52-62.

Bovaird, T. and Löffler, E. (2012), "From engagement to co-production: the contribution of users and communities to outcomes and public value", Voluntas, Vol. 23, pp. 1119-1138.

Brandsen, T. (2021), "Vulnerable citizens: will co-production make a difference?", in Loeffler, E. and Bovaird, T. (Eds), The Palgrave Handbook of Co-production of Public Services and Outcomes, Palgrave Macmillan, Cham, pp. 527-539.

Bryman, A. and Burgess, R. (Eds) (1994), Analysing Qualitative Data, Routledge, London.

Casula, M., Leonardi, C. and Zancanaro, M. (2020), "How does digital technology impact on the coproduction of local services? Evidence from a childcare experience", Public Money and Management. doi: 10.1080/09540962.2020.1728066.
Citizens as initiators of co-creation 
IJPSM

34,7

812

Charalabidis, Y., Loukis, E., Androutsopoulou, A., Karkaletsis, V. and Triantafillou, A. (2014), "Passive crowdsourcing in government using social media", European Journal of Marketing, Vol. 8 No. 2, pp. 283-308.

Chatman, E.A. (1991), "Life in a small world: applicability of gratification theory to information-seeking behavior", Journal of the American Society for Information Science, Vol. 42 No. 6, pp. 438-449.

Clifton, J., Díaz Fuentes, D. and Llamosas García, G. (2020), "ICT-enabled co-production of public services: barriers and enablers. A systematic review", Information Polity, Vol. 25 No. 1, pp. 25-48.

Dahlgren, P. and Alvares, C. (2013), "Political participation in an age of mediatisation", Javnost: The Public, Vol. 20 No. 2, pp. 47-65.

De Jong, M.D.T., Sharon, N. and Jansma, S.R. (2019), “Citizens' intentions to participate in governmental co-creation initiatives: comparing three co-creation configurations", Government Information Quarterly, Vol. 36 No. 3, pp. 490-500.

Driss, O.B., Mellouli, S. and Trabelsi, Z. (2019), "From citizens to government policy-makers", Government Information Quarterly, Vol. 36 No. 3, pp. 560-570.

Durose, C., Needham, C., Mangan, C. and Rees, J. (2017), "Generating 'good enough' evidence for coproduction”, Evidence and Policy, Vol. 13 No. 1, pp. 135-151.

Furlong, A. (2008), "The Japanese Hikikomori phenomenon: acute social withdrawal among young people", The Sociological Review, Vol. 56 No. 2, pp. 309-325.

Griffiths, T. (2002), "Gibbs sampling in the generative model of latent Dirichlet allocation", available at: http://www-psych.stanford.edu/ gruffydd/cogsci02/lda.ps.

Haasio, A. and Naka, H. (2019), "An analysis of information shared on hikikomoris discussion forums", Qualitative and Quantitative Methods in Libraries, Vol. 8 No. 4, pp. 509-523.

Healy, K. (2000), Social Work Practices: Contemporary Perspectives on Change, Sage, London.

Heinze, H.J. (2013), "Beyond a bed: support for positive development for youth residing in emergency shelters", Children and Youth Services Review, Vol. 35, pp. 278-286.

Husu, H.-M. and Välimäki, V. (2017), "Staying inside: social withdrawal of the young, Finnish 'Hikikomori”, Journal of Youth Studies, Vol. 20 No. 5, pp. 605-621.

Iwasaki, Y. (2016), "The role of youth engagement in positive youth development and social justice youth development for high-risk, marginalised youth", International Journal of Adolescence and Youth, Vol. 21 No. 3, pp. 267-278.

Jalonen, H. (2016), "Social networking sites (SNSs) - smart platforms for public service innovation?", International Journal of Virtual Communities and Social Networking, Vol. 8 No. 3, pp. 1-15.

Jilke, S. and Van de Walle, S. (2013), "Two track public services? Citizens' voice behaviour towards liberalized services in the EU15”, Public Management Review, Vol. 15 No. 4, pp. 465-476.

Jones, S. (1998), "Information, internet and community: notes toward an understanding of community in the information age", in Jones, S. (Eds), Cybersociety 2.0, Sage, Thousand Oaks, pp. 1-34.

Laihonen, H. and Mäntylä, S. (2017), "Principles of performance dialogue in public administration", International Journal of Public Sector Management, Vol. 30 No. 5, pp. 414-428.

Laihonen, H. and Rajala, T. (2020), "Developing public administration with performance dialogues", in Farazmand, A. (Ed.), Global Encyclopedia of Public Administration, Public Policy, and Governance, Springer, Cham.

Lambert, J. and Hessler, B. (2018), Digital Storytelling: Capturing Lives, Creating Community, Routledge, New York.

Larson, R.W. (2000), "Toward a psychology of positive youth development”, American Psychologist, Vol. 55 No. 1, pp. 170-183.

Lember, V., Brandsen, T. and Tõnurist, P. (2019), “The potential impacts of digital technologies on coproduction and co-creation", Public Management Review, Vol. 21 No. 11, pp. 1665-1686. 
Li, T.M.H. and Wong, P.W.C. (2015), "Youth social withdrawal behaviour (Hikikomori): a systematic review of qualitative and quantitative studies", Australian and New Zealand Journal of Psychiatry, Vol. 49 No. 7, pp. 595-609.

Lind, C., Walsh, C., McCaffrey, G., Wardle, M., Johansson, B. and Juby, B. (2019), "Youth strengths arise from the ashes of adversity", International Journal of Adolescence and Youth, Vol. 24 No. 3, pp. 274-281.

Linders, D. (2012), "From e-government to we-government: defining a typology for citizen coproduction in the age of social media”, Government Information Quarterly, Vol. 29 No. 4, pp. 446-454.

Liu, B. (2012), "Sentiment analysis and opinion mining", Synthesis Lectures on Human Language Technologies, Vol. 5 No. 1, pp. 1-167.

Lopes, T.S.A. and Alves, H. (2020), "Coproduction and cocreation in public care services: a systematic review”, International Journal of Public Sector Management, Vol. 33 No. 5, pp. 561-578.

Mergel, I. (2016), "Social media in the public sector", in Bearfield, D. and Dubnick, M. (Eds), Encyclopedia of Public Administration and Public Policy, Taylor \& Frances, Abingdon, pp. 3018-3021.

Meriluoto, T. (2018), "Turning experience into expertise. Technologies of the self in Finnish participatory social policy", Critical Policy Studies, Vol. 12 No. 3, pp. 294-313.

Mills, S. (2004), Discourse, Routledge, London.

Mulvale, G., Moll, S., Miatello, A., Robert, G., Larkin, M., Palmer, J.V., Powell, A., Gable, C. and Girling, M. (2019), "Codesigning health and other public services with vulnerable and disadvantaged populations: insights from an international collaboration”, Health Expectations, Vol. 22 No. 3, pp. 284-297.

Norden (2021), "Social policy and welfare", available at: https://www.norden.org/en/information/socialpolicy-and-welfare.

Nott, B.D. and Vuchinich, S. (2016), "Homeless adolescents' perceptions of positive development: a comparative study", Child Youth Care Forum, Vol. 45, pp. 865-886.

OECD (2019a), "Recommendation of the council on artificial intelligence", available at: https://www. oecd.org/going-digital/ai/principles/.

OECD (2019b), "Embracing innovation in government global trends", available at: https://www.oecd. org/innovation/innovative-government/embracing-innovation-in-government-global-trends2019.htm.

Osborne, S.P. (2018), "From public service-dominant logic to public service logic: are public service organizations capable of co-production and value co-creation?", Public Management Review, Vol. 20 No. 2, pp. 225-231.

Ponciano, L. (2013), "The voices of youth in foster care: a participant action research study", Action Research, Vol. 11 No. 4, pp. 322-336.

Potter, J. and Wetherell, M. (1987), Discourse and Social Psychology: Beyond Attitudes and Behaviour, Sage, London.

Puschmann, C. and Scheffer, T. (2016), Topic Modelling for Media and Communication Research: A Short Primer, HIIG Discussion Paper Series No. 2016-05.

Rogers, E.M. (2003), Diffusion of Innovations, Free Press, New York.

Sanders, J., Munford, R., Thimasarn-Anwar, T., Liebenberg, L. and Ungar, M. (2015), "The role of positive youth development practices in building resilience and enhancing wellbeing for at-risk youth", Child Abuse and Neglect, Vol. 42, pp. 40-53.

Shalev-Shwartz, S. and Ben-David, S. (2014), Understanding Machine Learning: From Theory to Algorithms, Cambridge University Press, New York.

Star, S. (2010), "This is not a boundary object: reflections on the origin of a concept", Science, Technology and Human Values, Vol. 35 No. 5, pp. 601-617. 
IJPSM

34,7

814

Sumner, R., Burrow, A.L. and Hill, P.L. (2018), "The development of purpose in life among adolescents who experience marginalization: potential opportunities and obstacles", American Psychologist, Vol. 73, pp. 740-752.

Trowbridge, H. and Willoughby, M. (2020), "Connecting voices, challenging perspectives and catalysing change: using storytelling as a tool for co-creation in public services across Europe", in Scott, J.W. (Ed.), Cross-Border Review, Yearbook 2020, Budapest, pp. 59-72.

Uppström, E. and Lönn, C.-M. (2017), "Explaining value co-creation and co-destruction in egovernment using boundary object theory", Government Information Quarterly, Vol. 34 No. 3, pp. 406-420.

Vainikka, E. (2020), "The anti-social network: precarious life in online conversations of the socially withdrawn”, European Journal of Cultural Studies, Vol. 23 No. 4, pp. 596-610.

Vargo, S.L. and Lusch, R.F. (2004), "Evolving to a new dominant logic for marketing", Journal of Marketing, Vol. 68 No. 1, pp. 1-17.

Voorberg, W.H., Bekkers, V.J.J.M. and Tummers, L.G. (2014), "A systematic review of co-creation and co-production: embarking on the social innovation journey", Public Management Review, Vol. 17 No. 9, pp. 1333-1357.

Vyas, D. and Dillahunt, T. (2017), "Everyday resilience: supporting resilient strategies among low socioeconomic status communities", PACM on Human-Computer Interaction, Vol. 1 No. 2, 105.

Wilson, R., Cornwell, C., Flanagan, E., Nielsen, N. and Khan, H. (2018), Good and Bad Help: How Purpose and Confidence Transform Lives, NESTA, London.

\section{Appendix}

Table A1.

Topics: all messages

\begin{tabular}{lcccc}
\hline Topics & Griffiths2004 & CaoJuan2009 & Arun2010 & Deveaud2014 \\
\hline 2 & -413189.8 & 0.05207234 & 2800.010 & 2.662396 \\
3 & -392841.3 & 0.06310903 & 2599.247 & 2.601560 \\
4 & -381438.1 & 0.04895806 & 2455.969 & 2.592959 \\
5 & -370926.7 & 0.05202274 & 2350.191 & 2.558961 \\
6 & -363997.6 & 0.04359119 & 2254.581 & 2.561207 \\
7 & -358434.6 & 0.03801782 & 2173.783 & 2.550152 \\
8 & -356168.9 & 0.04152681 & 2114.149 & 2.528784 \\
9 & -349520.8 & 0.04652782 & 2064.476 & 2.507224 \\
10 & -349209.4 & 0.04024766 & 2006.097 & 2.486549 \\
\hline
\end{tabular}

Table A2.

Topics: negative messages

\begin{tabular}{lcccc}
\hline Topics & Griffiths2004 & CaoJuan2009 & Arun2010 & Deveaud2014 \\
\hline 2 & -189266.5 & 0.04409785 & 3563.746 & 2.591690 \\
3 & -180603.2 & 0.05093707 & 3304.853 & 2.531278 \\
4 & -173851.8 & 0.05939551 & 3132.674 & 2.461443 \\
5 & -170388.1 & 0.04363732 & 2984.085 & 2.526094 \\
6 & -167305.7 & 0.04584996 & 2872.755 & 2.473483 \\
7 & -163433.3 & 0.04808042 & 2782.769 & 2.440567 \\
8 & -161566.8 & 0.04360709 & 2695.616 & 2.428754 \\
9 & -160271.6 & 0.04147533 & 2622.406 & 2.432945 \\
10 & -158343.3 & 0.04617000 & 2571.106 & 2.395541 \\
\hline
\end{tabular}


Citizens as initiators of co-creation

\begin{tabular}{lcccccc}
\hline & SS & df & \multicolumn{1}{c}{ MS } & $F$ & Prob > F & $N$ \\
\hline Topic 1 & 16097.7725 & 3 & 5365.92416 & 58.81 & $0.00 * * *$ & 803 \\
Topic 2 & 6625.77239 & 3 & 2208.5908 & 27.62 & $0.00^{* * *}$ & 822 \\
Topic 3 & 5339.65959 & 3 & 1779.88653 & 19.92 & $0.00 * * *$ & 753 \\
Topic 4 & 14588.7847 & 3 & 4862.92823 & 47.96 & $0.00 * * *$ & 728
\end{tabular}

Note(s): *significant at the 0.10 level, ** significant at the 0.05 level, *** significant at the 0.01 level

Table A3.

Analysis of variance (ANOVA): all messages

\begin{tabular}{lcc}
\hline & chi2(3) & Prob > chi2 \\
\hline Topic 1 & 497.6442 & $0.00^{* * *}$ \\
Topic 2 & 118.9233 & $0.00^{* * *}$ \\
Topic 3 & 183.9940 & $0.00^{* * *}$ \\
Topic 4 & 379.9907 & $0.00^{* * *}$
\end{tabular}

Note(s): *significant at the 0.10 level, ** significant at the 0.05 level, *** significant at the 0.01 level

Table A4. Bartlett's test for equal variances: all messages

\begin{tabular}{lcccccc}
\hline & SS & df & MS & $F$ & Prob $>F$ & $N$ \\
\hline Topic 1 & 6122.76125 & 2 & 3061.38063 & 48.48 & $0.00^{* * * *}$ & 528 \\
Topic 2 & 2362.70096 & 2 & 1181.35048 & 22.58 & $0.00^{* * *}$ & 491 \\
Topic 3 & 3800.20716 & 2 & 1900.10358 & 34.98 & $0.00^{* * *}$ & 515
\end{tabular}

Note(s): *significant at the 0.10 level, ** significant at the 0.05 level, *** significant at the 0.01 level

Table A5.

Analysis of variance (ANOVA): negative messages

\begin{tabular}{lrc}
\hline & chi2(2) & Prob > chi2 \\
\hline Topic 1 & 156.4093 & $0.00^{* * * *}$ \\
Topic 2 & 33.8816 & $0.00^{* * * *}$ \\
Topic 3 & 41.3105 & $0.00^{* * * *}$
\end{tabular}

Note(s): *significant at the 0.10 level, ** significant at the 0.05 level, *** significant at the 0.01 level

Table A6.

Bartlett's test for equal variances: negative messages

\begin{tabular}{lccccc}
\hline & Topic 1 & Topic 2 & Topic 3 & Topic 4 & sig. \\
\hline Anger & 1.13 & 1.60 & 1.33 & 1.35 & $0.00 * * *$ \\
Anticipations & 2.37 & 2.66 & 2.33 & 2.67 & $0.01 * * *$ \\
Disgust & 0.75 & 1.16 & 0.87 & 0.95 & $0.00 * * *$ \\
Fear & 1.58 & 2.33 & 1.69 & 2.06 & $0.00 * * *$ \\
Joy & 1.23 & 1.87 & 1.47 & 1.56 & $0.00 * * *$ \\
Sadness & 1.64 & 2.14 & 1.77 & 2.06 & $0.00 * * *$ \\
Surprise & 0.86 & 1.15 & 0.94 & 1.01 & $0.00 * * *$ \\
Trust & 2.57 & 3.31 & 2.66 & 3.02 & $0.00 * * *$ \\
Negative & 2.82 & 3.69 & 3.11 & 3.51 & $0.00 * * *$ \\
Positive & 4.42 & 5.29 & 4.62 & 5.06 & $0.00 * * *$
\end{tabular}

Note(s): *significant at the 0.10 level, ** significant at the 0.05 level, *** significant at the 0.01 level

Table A7. Sentiment analysis: all messages 


\begin{tabular}{|c|c|c|c|c|c|}
\hline $\begin{array}{l}\text { IJPSIM } \\
247\end{array}$ & & Topic 1 & Topic 2 & Topic 3 & sig. \\
\hline & Anger & 1.91 & 1.95 & 1.89 & ei \\
\hline & anticipation & 3.00 & 2.30 & 2.68 & $0.00 * * *$ \\
\hline & Disgust & 1.26 & 1.20 & 1.16 & ei \\
\hline & Fear & 2.72 & 2.19 & 2.59 & $0.00 * * *$ \\
\hline & Joy & 1.70 & 1.45 & 1.53 & $0.05 *$ \\
\hline 816 & Sadness & 2.49 & 2.06 & 2.44 & $0.00 * * *$ \\
\hline & Surprise & 1.26 & 1.13 & 1.21 & ei \\
\hline & Trust & 3.04 & 2.57 & 2.97 & $0.00 * * *$ \\
\hline & negative & 4.36 & 3.96 & 4.53 & $0.03 * *$ \\
\hline analysis: & Positive & 4.86 & 4.25 & 4.53 & $0.03 * *$ \\
\hline & Note(s): & 0.10 leve & at the 0 & nifican & vel \\
\hline
\end{tabular}

\section{Corresponding author}

Harri Jalonen can be contacted at: harri.jalonen@uwasa.fi

For instructions on how to order reprints of this article, please visit our website:

www.emeraldgrouppublishing.com/licensing/reprints.htm

Or contact us for further details: permissions@emeraldinsight.com 